\title{
Subjective Ratings of Floor Slippery on Common Indoor and Outdoor Floors
}

\author{
Oyun-Erdene Enkhjargal and Kai Way Li
}

\begin{abstract}
Slip and fall incidences are common both at work and in our daily lives. They are not only serious environmental safety issues but also important occupational safety and health problems. Floor slipperiness has been identified as one of the critical factors affecting the risk of slip and fall. Floor slipperiness may be quantified by measuring the coefficient of friction of the floor. It may also be determined by human judgements. How people perceive floor slipperiness is an important factor affecting the likelihood of a slip/fall incidence. The purpose of this study was to determine the difference of perceived floor slipperiness by human subjects under different floor roughness levels, floor conditions and sensation mode. Fifteen floor samples were tested under dry, wet, and soapy solution contaminated conditions. Twenty human subjects were recruited to rate the floor slipperiness of the floor samples using visual and tactile sensations. The results showed that the effects of the three factors on the subjective ratings were statistically significance $(p<0.0001)$. The two-way and three-way interaction effects were also significance $(p<0.0001)$. The results of the study are beneficial in housekeeping and safety training at workplaces to reduce slip \& fall incidences. The results of this study provide important information for slip and fall prevention.
\end{abstract}

Index Terms - Slip and fall, risk of fall, friction, subjective rating.

\section{INTRODUCTION}

As Mongolia is rapidly developing in the mining, construction and light industry, there are increasingly unfortunate cases of occupational hazard due to industrial accidents and occupational health and loss of work safety and performance. Due to the inadequate enforcement of labor safety and hygiene standards, the incidence of industrial accidents and occupational diseases hasn't decreased, and the lives and health of employees are worsening (NSOM, 2017). Figure 1 shows the percentage of accident type in 2017 in Mongolia (NOHSPM, 2017). Slips/falls has the highest percentage $(48.9 \%)$ in the statistics in June 2017. This identifies the significance of the prevention of slip/fall incidences.

Fall risk factors are commonly categorized as personal or environmental (Heiden et al., 2005). Personal factors include characteristics of the individual (such as age, functional abilities, and chronic conditions) while environmental risk factors usually refer to fall hazards in and around the home (such as tripping hazards, lack of stair railings or grab bars, and poor lighting).

Manuscript received Jan 9, 2019; revised July 12, 2019.This research was partially supported by a grant from the Ministry of Science \& Technology of the Republic of China under project MOST 106-2221-E-216-008-MY3.

Oyun-Erdene Enkhjargal and Kai Way Li are with the Department of Industrial Management, Chung Hua University, Hsin-Chu, Taiwan (e-mail: oyunerdene.enkhjargal@yahoo.com).
The risk of fall increases with the number of risk factors present and the effects of many risk factors increase with age. Fall risk can be reduced by modifying risk factors such as lower-body weakness, problems with gait and balance, use of psychoactive medications, and visual impairment. Identifying and treating symptoms of certain chronic diseases such as Parkinson's disease and arthritis also may reduce the risk of falling.

Floor slipperiness is a critical issue in slip and fall incidents which are a major source of occupational injuries ( $\mathrm{Li}$ et al, 2004; 2005). Accidents caused by slips and falls on slippery surfaces present a significant safety problem (Swensen et 1992; Gronqvist, 1995). Foot slips on floors are due to insufficient friction at the shoe sole and floor interface. Floor slipperiness may be measured via either an objective or a subjective approach. The former involves using a slipmeter to measure the friction coefficient at the footwear-floor interface. The latter involves collecting subjective ratings of perceived floor slipperiness from human subjects.

Perception of floor slipperiness, also essential to assessing slipperiness, could supplement objective measurements of slipperiness including friction measurement. Correlations between the perception and objective measures of slipperiness published in the literature were summarized by Chang et al. (2004). Myung et al. (1993) reported an inverse relationship between the subjective ranking and measured static COF; a lower measured COF value usually resulted in a more slippery subjective ranking. Cohen and Cohen (1994) reported significant disagreements between the measured COF values of the tiles and subjective responses obtained by visual comparison of the 23 tested tiles to a standard tile with a COF of 0.5. Swensen et al. (1992) reported that the correlations between the measured $\mathrm{COF}$ and subjective rating of the surface slipperiness of steel beams with different coatings were strong for both ironworkers $(r=0.75)$ and college students $(r=0.90)$.

Floor slipperiness is a major indicator in quantifying the risk of slips \& falls and friction measurement is one of the major approaches to identify floor slipperiness (Li et al., 2011, 2014; Yu et al., 2013; Yu and Li, 2015). Most published studies of friction measurements were conducted in laboratories using new floor surfaces and artificial contaminants that might not represent what most employees encounter daily. Footwear, floor, and surface condition may affect the friction on the floor (Li et al., 2012; 2018).

The objective of this study was to determine the difference 
of perceived floor slipperiness by human subjects under different floor surface and floor conditions for 15 commonly used floor tiles and to discuss their implications on slip \& fall prevention.

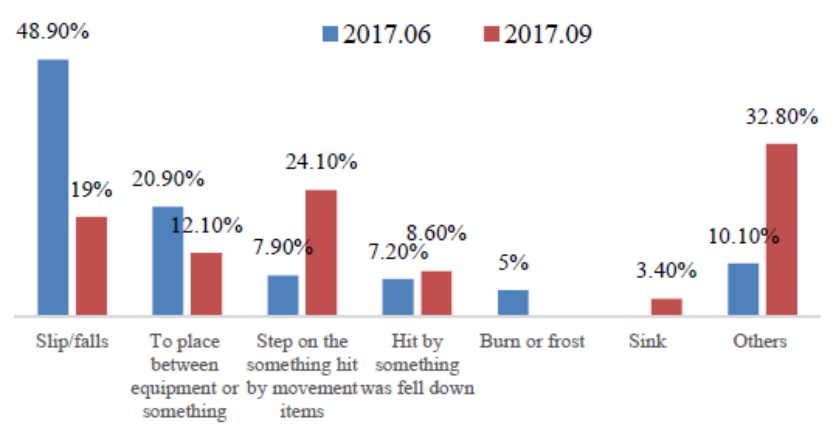

Fig. 1. The reasons of industrial accidents (2017) in Mongolia.

\section{METHODS}

A total of 20 subjects, 7 females and 13 males, participated in the study. All subjects joined for experiment voluntarily and randomized experimental design. The female subjects were $22.5( \pm 4.7)$ years old, $163 \mathrm{~cm}$ tall and had a mass of 62 $( \pm 9.3) \mathrm{kg}$. The male subjects were $21.6( \pm 3.6)$ years old, 173.2 $( \pm 5.2)$ tall and had a mass of $69.6( \pm 19.4) \mathrm{kg}$. All the subjects read and signed the informed consent. All the subjects reported no history of dizziness, vestibular disorders, neurological disorders or any orthopaedic abnormalities of the lower extremities within a year from the study.

The factors of the study included floor conditions and floor roughness. Fifteen floor samples were tested. The roughness parameters, $\mathrm{R}_{\mathrm{a}}$, of these floor samples were measured using a Mitutoyo profilometer.

\section{A. Floor Tiles}

Fifteen floor tiles were tested in this study. All of floors were ceramic and the dimensions of the floor tiles were included $9.7 \times 19.7 \mathrm{~cm} \mathrm{(2),} 44.6 \times 89.5 \mathrm{~cm} \mathrm{(2),} 29.9 \times 60 \mathrm{~cm} \mathrm{(7),}$ $32.4 \times 60 \mathrm{~cm}(1)$ and $14.7 \times 30 \mathrm{~cm}(3)$. For small sized floors $(9.7 \times 19.7 \mathrm{~cm})$, a plastic frame to accommodate the floor sample was used so as to fix the floor during the trial. Three floor conditions were tested under three surface conditions including dry, wet, and dishwashing detergent solution. Wet and detergent solution floors are common in all the buildings, especially kitchen and dining areas. For dry condition, clean dry floor was measured.

For wet surface, the floors were different size such as small size $(9.7 \times 19.7 \mathrm{~cm})$ and large size $(44.6 \times 89.5 \mathrm{~cm})$ hence, 200 $\mathrm{ml}$ of water was applied on the small sized floors, $500 \mathrm{ml}$ of water was applied on the large sized floors. (see Fig. 2).

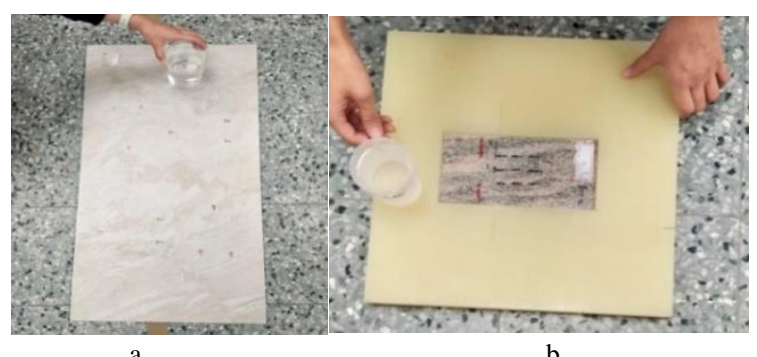

Fig. 2 a. Small sized floor with stable plate, b. large sized floor.
For the detergent solution, $200 \mathrm{ml}$ of water with $10 \%$ of dishwashing detergent and $500 \mathrm{ml}$ of water with $20 \%$ of dishwashing detergent solution was evenly applied across the testing area in the small and large floor samples, respectively.

\section{B. Subjects Survey of Floor Slipperiness}

To assess the perceived slipperiness of floor conditions, a subjective visual and tactile evaluation of slipperiness was conducted using the same floor tiles in the friction measurements.

The order of floor-surface conditions presented to each subject was randomly arranged. At least one day later, 10 subjects performed the different evaluation for the dry floor condition in the laboratory. For wet and detergent solution condition, five subjects performed the experiment at the same time depended on their available time. For visual assessments, the subjects were requested to watch the floor sample and then gave a rating of floor slipperiness. For tactile assessment, the subjects use their dominant barefoot to touch the floor sample and move their foot for approximately $20 \mathrm{~cm}$ forward and backward. The subjects then gave the floor slipperiness rating. A five-point scale was used for both of the visual and tactile rating of floor slipperiness: from 1 - extremely slippery to 5 - not slippery at all. A total of 1,800 surveys were collected and used for the statistical analysis.

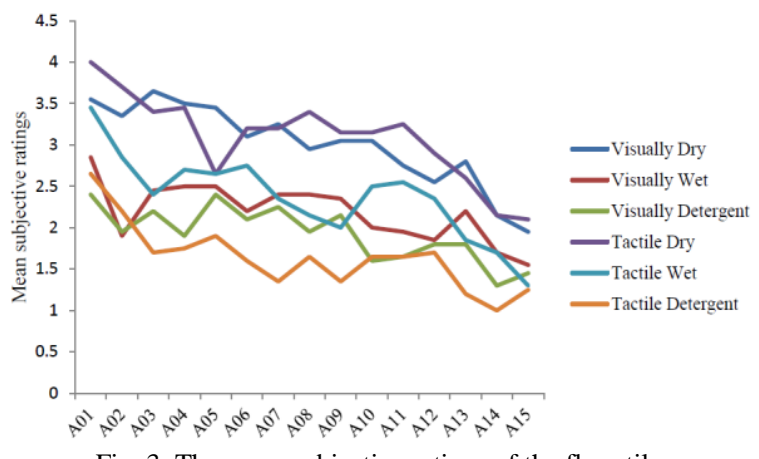

Fig. 3. The mean subjective ratings of the floor tiles.

\section{Procedure}

Each subject was given a notepad with test sheet. Subjects reported 1 to 5 on the table their perception during experiment. It was then explained that the subjects would be rating a series of surfaces for slipperiness, using the provided scale. As above mentioned, a rating score of " 1 " indicated "extremely slippery", while a rating score of " 5 " corresponded to "not slippery at all".

First, the surface was brushed down to remove any loose dirt. Then, the subject was asked to look at the surface, and rate its perceived "slipperiness" on the scale with (1 to 5) to mark its location. Then, the subject was asked to touch the surface by barefoot, and rate it again. To touch the surface, the subjects touched four times in one direction. The right foot was dominated. And then, for wet condition, the subjects were asked to look and touch by barefoot on the wet surface that was applied by water and rate it again and marked on the test sheet. For detergent solution condition, it was same as the above way.

\section{Statistical Analysis}

There were a total of 1,800 trials (20 subjects $* 15$ floor 
tiles $* 3$ floor condition $* 2$ modes such as visually and tactile). An analysis of variance (ANOVA) was used to determine the effects of surface condition significant on the ratings of visual and tactile. A Duncan's multiple range test were also used to examine the differences among the floors in the roughness values and perception ratings in which the results from all kind of floor.

\section{RESULTS AND DISCUSSION}

Table I shows the mean and standard deviation of the subjective ratings. All the mean ratings were 4 (A01) or less and generally high on the dry condition. For all floors, A14 with detergent solution condition by tactile (1) was the lowest.

TABLE I. SUBJECTIVE RATINGS OF FLOOR SLIPPERY UNDER EXPERIMENTAL CONDITIONS

\begin{tabular}{|c|c|c|c|c|c|c|c|c|c|c|c|c|c|}
\hline & \multirow[b]{3}{*}{ Floor } & \multicolumn{6}{|c|}{ Visually } & \multicolumn{6}{|c|}{ Tactile } \\
\hline & & \multicolumn{2}{|c|}{ Dry } & \multicolumn{2}{|c|}{ Wet } & \multicolumn{2}{|c|}{ Detergent } & \multicolumn{2}{|c|}{ Dry } & \multicolumn{2}{|c|}{ Wet } & \multicolumn{2}{|c|}{ Detergent } \\
\hline & & Mean & Std & Mean & Std & Mean & Std & Mean & Std & Mean & Std & Mean & Std \\
\hline 1 & A01 & 3.55 & 0.88 & 2.85 & 0.81 & 2.4 & 0.68 & 4 & 1.02 & 3.45 & 0.88 & 2.65 & 1.08 \\
\hline 2 & A02 & 3.35 & 1.03 & 1.9 & 0.71 & 1.95 & 0.94 & 3.7 & 0.92 & 2.85 & 0.81 & 2.2 & 0.69 \\
\hline 3 & A03 & 3.65 & 1.03 & 2.45 & 0.82 & 2.2 & 0.95 & 3.4 & 0.88 & 2.4 & 1.18 & 1.7 & 0.92 \\
\hline 4 & A04 & 3.5 & 1.1 & 2.5 & 0.82 & 1.9 & 0.64 & 3.45 & 1.19 & 2.7 & 0.97 & 1.75 & 0.78 \\
\hline 5 & A05 & 3.45 & 0.88 & 2.5 & 0.68 & 2.4 & 0.82 & 2.65 & 1.34 & 2.65 & 1.08 & 1.9 & 0.71 \\
\hline 6 & A06 & 3.1 & 1.16 & 2.2 & 0.69 & 2.1 & 0.71 & 3.2 & 1.1 & 2.75 & 0.85 & 1.6 & 0.88 \\
\hline 7 & A07 & 3.25 & 0.85 & 2.4 & 0.75 & 2.25 & 1.01 & 3.2 & 0.95 & 2.35 & 1.18 & 1.35 & 0.48 \\
\hline 8 & A08 & 2.95 & 0.88 & 2.4 & 0.82 & 1.95 & 0.82 & 3.4 & 0.68 & 2.15 & 1.13 & 1.65 & 0.74 \\
\hline 9 & A09 & 3.05 & 1.05 & 2.35 & 0.98 & 2.15 & 0.81 & 3.15 & 1.22 & 2 & 0.85 & 1.35 & 0.48 \\
\hline 10 & A10 & 3.05 & 1.14 & 2 & 0.91 & 1.6 & 0.68 & 3.15 & 1.08 & 2.5 & 0.94 & 1.65 & 0.74 \\
\hline 11 & A11 & 2.75 & 1.11 & 1.95 & 0.82 & 1.65 & 0.58 & 3.25 & 0.96 & 2.55 & 0.99 & 1.65 & 0.74 \\
\hline 12 & A12 & 2.55 & 1.09 & 1.85 & 0.87 & 1.8 & 0.83 & 2.9 & 1.25 & 2.35 & 1.03 & 1.7 & 0.57 \\
\hline 13 & A13 & 2.8 & 1.19 & 2.2 & 0.69 & 1.8 & 1 & 2.6 & 1.23 & 1.85 & 1.03 & 1.2 & 0.52 \\
\hline 14 & A14 & 2.15 & 1.03 & 1.7 & 0.73 & 1.3 & 0.47 & 2.15 & 1.08 & 1.7 & 0.86 & 1 & 0 \\
\hline 15 & A15 & 1.95 & 0.94 & 1.55 & 0.68 & 1.45 & 0.6 & 2.1 & 1.33 & 1.3 & 0.47 & 1.25 & 0.71 \\
\hline
\end{tabular}

TABLE II. ANOVA TABLES FOR RATINGS

\begin{tabular}{lrrrrr}
\hline \multicolumn{6}{c}{ TABLE II. } \\
Source & DF & \multicolumn{1}{c}{ SS } & MS & F & p-value \\
\hline Model & 89 & 842.46 & 9.46 & 11.36 & $<0.0001$ \\
Error & 1710 & 1424.85 & 0.83 & & \\
Corrected Total & 1799 & 2267.31 & & & \\
\hline
\end{tabular}

TABLE III. THE Two-WAY AND THREE-WAy INTERACTION EFFECTS

\begin{tabular}{lrrrrr}
\hline Source & DF & \multicolumn{1}{c}{ SS } & \multicolumn{1}{c}{ MS } & \multicolumn{1}{c}{ F } & $p$ value \\
\hline Floor & 14 & 254.37 & 18.16 & 21.81 & $<0.0001$ \\
Surface & 2 & 486.27 & 243.13 & 291.8 & $<0.0001$ \\
Floor*surface & 28 & 26.79 & 0.95 & 1.15 & 0.27 \\
Mode & 1 & 0.02 & 0.02 & 0.03 & 0.85 \\
Floor*mode & 14 & 39.59 & 2.82 & 3.39 & $<0.0001$ \\
Surface*mode & 2 & 18.3 & 9.15 & 10.98 & $<0.0001$ \\
Floor*surface*mode & 28 & 17.09 & 0.61 & 0.73 & 0.84 \\
\hline
\end{tabular}

TABLE IV. DUNCAN's MULTIPLE RANGE TEST RESUltS FOR FLOOR

\begin{tabular}{lclccl}
\hline Floor & Mean & Group & Floor & Mean & Group \\
\hline A01 & 3.15 & A & A09 & 2.34 & C D E \\
A02 & 2.65 & B & A10 & 2.32 & D E F \\
A03 & 2.63 & B & A11 & 2.3 & D E F \\
A04 & 2.63 & B & A12 & 2.19 & E F \\
A05 & 2.59 & B C & A13 & 2.07 & F \\
A06 & 2.49 & B C D & A14 & 1.66 & G \\
A07 & 2.46 & B C D & A15 & 1.6 & G \\
A08 & 2.41 & B C D & & & \\
\hline
\end{tabular}

Note: Different letters in Duncan's group means they were significantly $(p<0.05)$ different.

\begin{tabular}{ccc}
\multicolumn{2}{c}{ TABLE V. DUNCAN’s MULTIPLE RANGE TEST RESUlT FOR SURFACE } \\
\hline SURFACE & MEAN & DUNCAN GROUPING \\
\hline DRY & 3.04 & $\mathrm{~A}$ \\
WET & 2.27 & $\mathrm{~B}$ \\
DETERGENT & 1.78 & $\mathrm{C}$ \\
SOLUTION & & \\
\hline
\end{tabular}

Note: Different letters in Duncan's group means they were significantly $(\mathrm{p}<0.05)$ different.
A01 (4) with dry condition by tactile and A02 (3.7) with dry condition by tactile were the highest.

An analysis of variance (ANOVA) was performed to determine the effects of the floor, surface and mode as visually and tactile factors on the measured subjective ratings. The results showed that the effects of the three factors on the subjective ratings were statistically significance $(p<0.0001)$ (see Table II). The two-way and three-way interaction effects were also significance ( $p<0.0001)$ (see Table III). Duncan's multiple range tests were performed to compare the difference between the each variable. Table IV shows the Duncan's multiple range test result for floors. The A01 (3.15) was significantly $(p<0.05)$ higher than A02 (2.65), A03 (2.63), A04 (2.63), A05 (2.59), A06 (2.49), A07 (2.46), A08 (2.41), A09 (2.34), A10 (2.32), A11 (2.3), A12 (2.19), A013 (2.07), A014 (1.66) and A15 (1.6). The A02, A03, A04, A05, $\mathrm{A} 06, \mathrm{~A} 07$ and A08 were both significantly $(p<0.05)$ higher than A09, A10, A11, A12, A13, A14 and A15. The A09 was significantly higher than A13, A14 and A15. The A10, A11, A12 and A13 were significantly higher than A14 and A15.

Table V shows the Duncan's multiple range test result for surface. The dry surface (3.04) was significantly $(p<0.05)$ higher than wet surface (2.27) and detergent solution surface (1.78). The wet surface (2.27) was significant $(p<0.05)$ higher than detergent solution surface (1.78). Duncan's multiple range tests results for mode as visually and tactile. The visually and tactile were significantly $(p<0.05)$ different.

The perceived floor slipperiness ratings were significant $(p<0.001)$ under different surface conditions. The detergent solution condition was the most slippery one, followed by the wet condition, and finally the dry condition. For floor, the subjective ratings of floors slipperiness were significantly ( $p<0.001)$. The subjects rated the A01 and A02 floors with the rough surface as the least slippery that means not slippery 
floor but comparison of the condition, A01 floors was ranked at somewhat slippery in dry condition on the tactile. The A14 floor was rated as most slippery with detergent solution condition on the tactile. Also, the A15 floor was rated as the extremely slippery with all condition except detergent on the tactile. Most floors were ranked high on the visual tests. However, some of these floors were ranked as very slippery in the tactile test.

\section{CONCLUSION}

It was appeared that the subjective ratings of floor slipperiness were significantly affected by floor surface condition. The detergent solution condition had higher ratings than those of the wet and dry conditions. However, it depends also on the roughness of the floors. Roughness floors were associated with less slipperiness ratings. In addition, floors without glaze might absorb the spilled liquid and hence reduced the effects of squeeze film at the footwear-floor interface. The subjective ratings results showed that the subjects could differentiate floor slipperiness when the surface conditions of the floor were clearly visible. However, the subjects were poor at rating raw materials of some ceramic floors for slipperiness. The results of the study were beneficial in planning housekeeping and safety training for employees for business where liquid contaminations are likely (such as dining service industry) to prevent slip \& fall incidences.

\section{ACKNOWLEDGMENTS}

This research was partially supported by a grant from the Ministry of Science \& Technology of the Republic of China under project MOST 106-2221-E-216-008-MY3.

\section{REFERENCES}

[1] W. R. Chang, K. W. Li, Y. H. Huang, A. Filiaggi, and T. K. Courtney, "Assessing floor slipperiness in fast-food restaurants in Taiwan using objective and subjective measures," Appl Ergon, vol. 35, pp. 401-408, 2004.

[2] H. H. Cohen and D. M. Cohen, "Perceptions of walking surface slipperiness under realistic conditions, utilizing a slipperiness rating scale," Journal of Safety Research, vol. 25, pp. 27-31, 1994.

[3] R. Grönqvist, "Mechanisms of friction and assessment of slip resistance of new and used footwear soles on contaminated floors," Ergonomics, vol. 38, no. 2, pp. 224-241, 1995.

[4] T. L. Heiden, D. J. Sanderson, J. T. Inglis, and G. P. Siegmund, "Adaptations to normal human gait on potentially slippery surfaces: The effects of awareness and prior slip experience," Gait \& Posture, vol. 24, pp. 237-246, 2005.

[5] K. W. Li, W. R. Chang, T. B. Leamon, and C. J. Chen, "Floor slipperiness measurement: Friction coefficient, roughness of floors, and subjective perception under spillage conditions," Safety Science, vol. 42, pp. 891-903, 2004.
[6] K. W. Li, W. R. Chang, J. C. Wei, and C. H. Kou, "Friction measurements on ramps using the Brungraber Mark II slipmeter," Safety Science, vol. 44, pp. 375-386, 2005.

[7] K. W. Li, Y. W. Hsu, W. R. Chang, and C. H. Lin, "Friction measurements on three commonly used floors on a college campus under dry, wet, and sand-covered conditions," Safety Science, vol. 45, no. 9, pp. 980-992, 2007.

[8] K. W. Li, R. F. Yu, and W. Zhang, "Roughness and slipperiness of floor surface: Tactile sensation and perception," Safety Science, vol. 49, pp. 508-512, 2011.

[9] K. W. Li, C. Y. Chen, C. C. Chen, and L. Liu, "Assessment of slip resistance under footwear materials, tread designs, floor contamination, and floor inclination conditions," Work, vol. 41, pp. 3349-3351, 2012.

[10] K. W. Li, F. Meng, and W. Zhang, "Friction between footwear and floor covered with solid particles under dry \& wet conditions," International Journal of Occupational Safety and Ergonomics, vol. 20, no. 1, 43-53, 2014.

[11] K. W. Li, C. Zhao, and L. Peng, "Subjective assessments of floor slipperiness before and after walk under two lighting conditions," International Journal of Occupational Safety and Ergonomics, vol. 24, pp. 294-302.

[12] R. Myung, J. L. Smith, and T. B. Leamon, "Subjective assessment of floor slipperiness," Int. J. Ind. Ergon, vol. 11, pp. 313-319.

[13] Social Snsurance General Office, Government of Mongolia, "The social insurance," Annual Report, 2016, pp. 26-28.

[14] E. E. Swensen, J. L. Purswell, R. E. Schlegel, and R. L. Stanevich, "Coefficient of friction and subjective assessment of slippery work surface," Hum. Factors, vol. 34, no. 1, pp. 67-77, 1992.

[15] The 4th National Occupational Health and Safety Program of Mongolia (NOHSPM), The 122th appendix of government resolution in 2012.

[16] The National Statistics Office of Mongolia (NSOM), 'Socio-economic situation of Mongolia," 2017, pp. 8-10.

[17] The 5th National Occupational Health and Safety Program of Mongolia, The 243th appendix of government resolution in 2017.

[18] R. F. Yu and K. W. Li, "A field assessment of floor slipperiness in a student cafeteria," International Journal of Injury Control and Safety Promotion, vol. 20, no. 3, pp. 245-253, 2013.

[19] R. Yu and K. W. Li, "Perceived floor slipperiness and floor roughness in a gait experiment," Work, vol. 50, pp. 649-657, 2015.

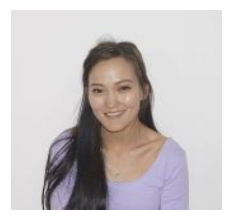

Oyun-Erdene Enkhjargal is from the Department of Industrial Management, Chung Hua University, HsinChu, Taiwan. Her research interests is industrial engineering

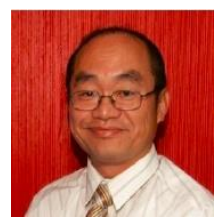

Kai Way Li is from the Department of Industrial Management, Chung Hua University, Hsin-Chu, Taiwan. His research interests are Ergonomics slip and falls, muscular fatigue. 